\title{
Determining Teachers' Educational Needs Regarding School Education Projects within the Scope of Erasmus + Programme
}

\author{
Fatma Karakuş ${ }^{1}$, Melis Yeşilpınar Uyar $^{2}$, Nur Leman Balbağ ${ }^{3}$ \\ ${ }^{1}$ Çukurova University, Faculty of Education, Department of Primary Education, Adana, Turkey \\ ${ }^{2}$ Çukurova University, Faculty of Education, Department of Educational Sciences, Adana, Turkey \\ ${ }^{3}$ Uşak University, Faculty of Education, Department of Primary Education, Uşak, Turkey \\ Correspondence: Melis Yeşilpınar Uyar, Çukurova University, Faculty of Education, Department of Educational Sciences, \\ Adana, Turkey.
}

Received: September 14, 2017

Accepted: October 10, $2017 \quad$ Online Published: October 12, 2017

doi:10.11114/jets.v5i11.2653

URL: https://doi.org/10.11114/jets.v5i11.2653

\begin{abstract}
The purpose of this study was to determine teachers' educational needs regarding school education projects within the scope of Erasmus + programme. In the study, the case study method, one of qualitative research designs, was used. The participants were determined using the snowball sampling method, and eight secondary school teachers took part in the study. The research data were collected via semi-structured interviews and analyzed using the inductive analysis method. The results of the analysis revealed that the teachers had certain knowledge about the processes of planning, implementation and evaluation of the projects and that they did not acquire the necessary related skills at all, though. It was also found that the group work process and lack of related knowledge, skills and experience were among the factors making the functioning of the process difficult and that professional development was not fully achieved. All these results demonstrate that teachers are need of an in-service training which focuses more on the steps of the application process and on the integration of the objectives of the process into the curriculum and which aims to help acquire the related skills considering the functioning of the process as a whole.
\end{abstract}

Keywords: Erasmus+, European Union project, needs analysis, teacher training

\section{Introduction}

Erasmus + programme, which is executed within the scope of European Union Education and Youth Programme, is applied in years from 2014 to 2020. The programme, which covers the fields of education, teaching, youth and sports, aims to help individuals acquire new skills regardless of their ages and educational backgrounds, to develop their personal developments and to increase their opportunities of employment. When the activity areas of the programme are examined with respect to teachers' professional development and students' education, it is seen that the programme simultaneously providing both teachers and students with the related services functions in the area of the activities of "Strategical Partnerships in School Education" within the scope of the main action of "Cooperation for Innovation and Exchange of Good Practices" (Center for European Union Education and Youth Programmes, 2017a).

The activity area of Strategical Partnerships in School Education is a follow-up of Comenius Program, which was put into practice between 2007 and 2013 and which was found among the education and youth programmes most popular in Turkey in those years. The programme provides service for the purposes of developing, transferring and/or applying innovative practices at institutional, local/regional, national or international levels and supports strategical partnership projects among the educational institutions in member countries of the programme (Center for European Union Education and Youth Programmes, 2017b). In addition, the activity area in question aims to let the education staff and students recognize different cultures, to help acquire the life skills necessary for personal development and for becoming an effective European citizen, to encourage raising awareness of various cultures and to develop teachers' skills in the area of international education. Barzanò (2002) states that with Erasmus + projects, teachers are provided with the opportunity to work in different areas in which they can develop their social skills, effective communication skills and group-work skills.

When viewed from a general viewpoint, it is seen that European Union projects contribute positively to the 
development of all the individuals in the Project team, support especially teachers' personal and professional development, and make important contributions to the education system as these projects allow learning about different education systems and making related comparisons (Aydoğan \& Şahin, 2006; Bozak, Konan \& Özdemir, 2016; Demircioğlu, Yavuz-Konokman \& Akay, 2015; Haspolat \& Özkılıç, 2007; Lembet, 2008; Öztürk, 2016). When viewed from the school dimension, especially strategical partnerships are reported to develop the relationships between students and teachers as well as between teachers and administrators, to increase parents' interest in school, to let students participate in the process, to develop students' self-confidence and to provide participants with the opportunity to recognize and investigate their own cultures (Acir, 2008; Aydoğan \& Şahin, 2006; Bahadır, 2007; Dilekli, 2008; Öksüm-Erdoğan, 2009). In addition, project processes provide institutions with the opportunity to do self-evaluation with a more autonomous approach and to determine their areas they need to develop (Barzanò, 2002).

When international studies carried out on European Union projects are examined, it is seen that school partnership projects contribute to the development of teachers and students as well as to the development of local governments, increase teachers' professional knowledge and skills, their social skills and personal responsibilities, and develop their language proficiencies (Dumitrescu, Drăghicescu, Olteanu \& Suduc, 2014; Liduma, 2014; Talmo, Radojicic, Orevi \& Mogli, 2014; Vabo, 2007). In addition, it is reported that project processes increase students' motivation, make positive contributions to the development of innovative teaching approaches, and improve the communication between teachers and students (Barzanò, 2002; Dumitrescu et.al., 2014; Gutiérrez Colón-Plana, 2012; Helsinki University, 2003; Somekh et.al., 2007; Talmo et.al., 2014; Thorsteinsson \& Page, 2008; Viladot et.al., 2017).

When studies in related literature were taken into account within the context of Turkey, it was seen that most of the studies include national reports and studies conducted by commissions (Kulaksiz, 2010). Besides, it was found that some of the studies evaluated the project processes and their effects with respect to the views of students, teachers and administrators. It was also seen that these studies allowed participants to learn about and understand different cultures, to raise their awareness of these different cultures, encouraged intercultural communication and developed the participants' language skills (Akay \& Yanpar-Yelken, 2012; Aydoğan \& Şahin, 2016; Bozak, Konan \& Özdemir, 2016; Haspolat \& Özkılıç, 2007; Kesik \& Balcı, 2016; Kulaksız, 2010; Tatlı, 2016; Öztürk, 2016; Yalçın-İncik \& Yanpar-Yelken, 2009).

The results obtained in both national and international studies demonstrate that European Union projects mostly make positive contributions to participants and institutions. On the other hand, it is seen that some other studies reported in related literature focused on the difficulties and problems experienced in the whole project process. For instance, in one study carried out by Kassel (2007), it was revealed that the problems experienced in the process of conducting Erasmus ${ }^{+}$projects included local administrators and teachers' lack of interest and support regarding the process who are all actually expected to take an active role in the process or. Yalçın-İncik and Yanpar-Yelken (2009) point out that participants experience problems in terms of working in groups and taking responsibility in the process of conducting the projects, while Haspolat and Özkılıç (2007) state that the most important difficulty experienced by project coordinators is related to finding a partner and filling out the application forms. In addition, Kulaksiz (2010) reports that school education projects contribute to the encouragement of intercultural communication and that the projects do not help increase the quality at all, though. Also, other similar studies demonstrating that participants experience difficulty especially in the application process suggest increasing their levels of knowledge and project processes (Bahadır, 2007; Bozak, Konan \& Özdemir, 2016; Helsinki University, 2003; Türkoğlu \& Türkoğlu, 2006).

In European Union Education and Youth Programmes, which involve Norway, Liechtenstein, Iceland, Switzerland and Croatia apart from 27 European Union countries, The Turkish National Agency ranks first among 33 countries that apply the programme in terms of the total number of requests for project applications in Europe. This situation demonstrates that European Union projects receives more interest in Turkey every passing year and that the number of projects prepared is increasing gradually. Considering this interest in European Union projects, it could be stated that it is important to determine participants' educational needs regarding the process of project preparation not only with respect to experiencing fewer problems in the phases of preparing, conducting and evaluating the projects but also in terms of allowing participants and institutions to benefit most from the process. In this respect, the present study aimed to determine the educational needs of teachers regarding the school education projects within the scope of Erasmus + . In line with this purpose, the following research questions were directed:

- What are activities carried out by teachers in the processes of planning, implementation and evaluation of the projects?

- What are personal and professional contributions of projects to participants?

- What are the problems experienced by teachers in the process of executing the projects?

- What are teachers' suggestions regarding the development of the project processes? 


\section{Method}

In the present study, which aimed to determine teachers' educational needs regarding school education projects within the scope of Erasmus + , the case study method, one of qualitative research methods, was used. Case studies are empirical studies which examine an up-to-date phenomenon in its real-life context (Yin, 2013). As in other qualitative research approaches, a case study does not serve the purpose of generalization, it allows in-depth examination considering various units ranging from a single individual to a school (Lichtman, 2012). In the present study, the activities of planning, implementation and evaluation carried out by teachers in project processes constituted the analysis units, and with the help of these activities, the problems experienced in the process and the areas that needed development were subjected to in-depth examination. Therefore, in the study, the case study method was adopted.

\subsection{Participants}

The study was carried out in the Spring Term of the academic year of 2016-2017 with teachers working at schools in different cities which belonged to the Ministry of National Education. While selecting the participants, the snowball sampling method, one of purposeful sampling methods, was used. In this respect, semi-structured interviews were held with a total of eight teachers. The snowball chain sampling method was used as it is an effective method used for determining individuals who can constitute a rich source of data regarding the problem. In this method, the process starts with the question of "Who could have the most information about this subject? Who would you like me to interview in relation to this subject?". The number of names determined in line with the progress in the process increases like a snowball (Yıldırım \& Şimşek, 2006). In this way, the individuals to be interviewed are determined, and the number of these individuals starts to decrease. In the present study, the first interview was held with the teacher coded as Oya, and the sample group was then expanded by directing the question of "Who would you like me to interview?". Table 1 presents personal information about the teachers participating in the study.

Table 1. Characteristics of the participants

\begin{tabular}{|c|c|c|}
\hline Variables & $\begin{array}{l}\text { Dimensions of } \\
\text { Variables }\end{array}$ & Participants \\
\hline \multirow{3}{*}{$\begin{array}{l}\text { Socio-Economic Level of the } \\
\text { School }\end{array}$} & Low & Sibel \\
\hline & Middle & Derya, Sinan, Melih, Banu, Oya, Ahmet \\
\hline & High & Selim \\
\hline \multirow{2}{*}{ Gender } & Female & Derya, Banu, Oya, Sibel \\
\hline & Male & Sinan, Melih, Ahmet, Selim \\
\hline \multirow{3}{*}{ Year of Professional Experience } & 5 to 10 years & Selim \\
\hline & 11 to 14 years & Derya, Sinan, Melih, Banu, Ahmet, Sibel \\
\hline & 20 years & Oya \\
\hline \multirow{4}{*}{ Field of Teaching } & Social Sciences & Derya, Sinan \\
\hline & Science & Banu, Sibel \\
\hline & English Language & Oya, Ahmet, Selim \\
\hline & Music & Melih \\
\hline \multirow{2}{*}{ Educational Background } & Bachelor's Degree & Derya, Sinan, Melih, Banu, Oya, Selim, Sibel \\
\hline & Master of Arts & Ahmet \\
\hline \multirow{2}{*}{$\begin{array}{l}\text { Participation in } \text { In-Service } \\
\text { Training }\end{array}$} & Yes & Oya, Ahmet \\
\hline & No & Derya, Sinan, Melih, Banu, Selim, Sibel \\
\hline \multirow{3}{*}{ Duties in Projects } & Coordinator & Banu, Oya, Ahmet \\
\hline & Project Member & Derya, Sinan, Melih, Selim, Sibel \\
\hline & $\begin{array}{l}\text { Legal } \\
\text { Representative }\end{array}$ & Ahmet \\
\hline \multirow{2}{*}{$\begin{array}{l}\text { Total Number of Projects } \\
\text { Done/In Progress }\end{array}$} & Between 1-5 & Derya, Sinan, Selim, Sibel, Melih, Ahmet, Banu \\
\hline & 8 projects & Oya \\
\hline
\end{tabular}


As can be seen in Table 1, of all the teachers participating in the study, two of them were teachers at schools belonging to low and high socio-economic levels, while six of them worked at schools belonging to the middle socio-economic level. Moreover, four of the teachers were female, and four of them were male. When the teachers' years of professional experience were examined, it was seen that one teacher had a teaching experience between 5 and 10 years; that one had a teaching experience for more than 10 years; and that six teachers had a teaching experience between 11 and 14 years. In addition, it was found that two of the teachers had taken training on Erasmus + projects, while three of them worked in projects as a coordinator; four as project members and only one as a legal representative in projects. Also, it was revealed that one teacher took part in eight projects and that the rest of the teachers took part in 1 to 5 projects.

\subsection{Data Collection and Analysis}

In order to collect the research data, the interview method was applied. During the interviews, semi-structured interview forms prepared by the researchers were used. In this respect, the teachers were directed questions to obtain personal information about them (year of professional experience, field of teaching, educational background, project experience and so on). Following this, the teachers were directed questions to identify the activities they carried out in the processes of planning, applying and evaluating school education projects, to reveal the personal and professional contributions of their project works, to determine the problems they experienced in their project processes as well as to determine their suggested solutions to these problems. The interviews held on face-to-face basis lasted between 30 and 150 minutes.

The research data collected via the interviews were analyzed using the method of inductive analysis. In this respect, first, the data were arranged and coded. Next, the related categories were formed, and the models showing the relationships between the categories were formed.

In the study, for the data gathered with the qualitative data collection tools, the credibility, transferability and consistency criteria were used (Lincoln \& Guba, 1985 cited in Yıldırım \& Şimşek, 2006). Also, in the study, in order to ensure credibility, expert views and participants' confirmation were used for the development of the data collection tools and for the analysis of the data. In the methodology part of the study, the participants were informed in detail about the preparation of the data collection tools, about the data collection process and about the analysis of the data. In the study, to ensure the criterion of transferability, the research process was described in detail, and frequent quotations were used in the findings part of the study. As for consistency and confirmability of the study, experts were asked for their views about all the processes from the preparation of the data collection tools to the analysis of the data. As a result of the discussions held with the experts, the categories and the codes were finalized. In addition, for the analysis of the data, a computer-aided qualitative data analysis software was used to increase the validity and reliability of the study.

\section{Results}

This part presents the findings obtained in the study under sub-headings.

\subsection{Activities Carried out in the Processes of Planning, Implementation and Evaluation of the Project Works}

This part presents the findings regarding the activities the teachers carried out while conducting their project works in a way to include the related dimensions of planning, implementation and evaluation. Figure 1 shows the categories and the sub-categories regarding the activities the teachers carried out in the preparation process.

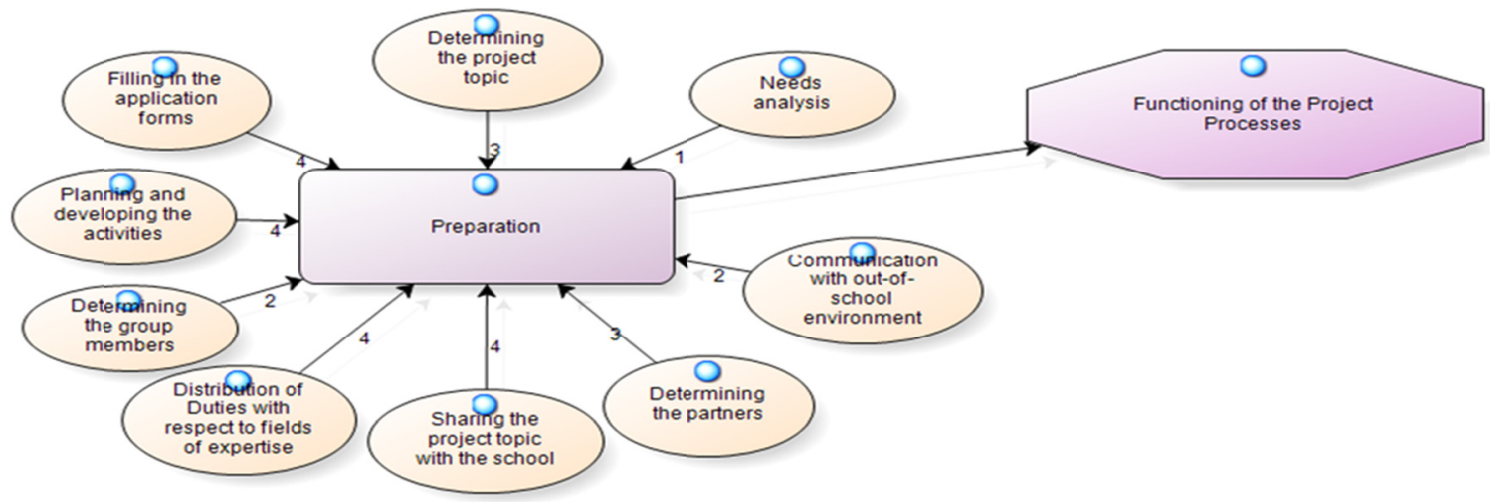

Figure 1. Activities carried out in the preparation process of the project works

When Figure 1 is examined, it is seen that in the process of preparation of the school education projects, the teachers determined the project topics, filled in the application forms, planned and developed the activities, determined the group members, distributed the duties in line with the fields of expertise and shared the project topic with the school. In addition, two of the participants stated that they established communication with the out-of-school environment, and 
one participant reported that s/he conducted needs analysis. All the participants, who explained in detail the processes of determining the project topic, the partners and the group members, filling in the application forms and establishing communication with the out-of-school environment, were found to work as a coordinator in the process. In relation to determining the project topic, one of the teachers said:

There is an idea put forward, and we evaluate this project idea according to the needs of the institution, its culture, its current location, or its expectations. The project idea is supposed to include originality. Of course, similar projects might have been conducted before, or the project idea might have been put into practice previously, but we should remember that everyone has their own peculiar style. If we can express ourselves well in our application form... we can reshape the idea. I mean there is no need to rediscover America; we won't do anything that has never tried before. Our project idea should be meaningful to others (Oya, p. 6-7).

Figure 2 illustrates the categories and the sub-categories regarding the activities the teachers who completed the planning process carried out in the processes of conducting and monitoring their project works.

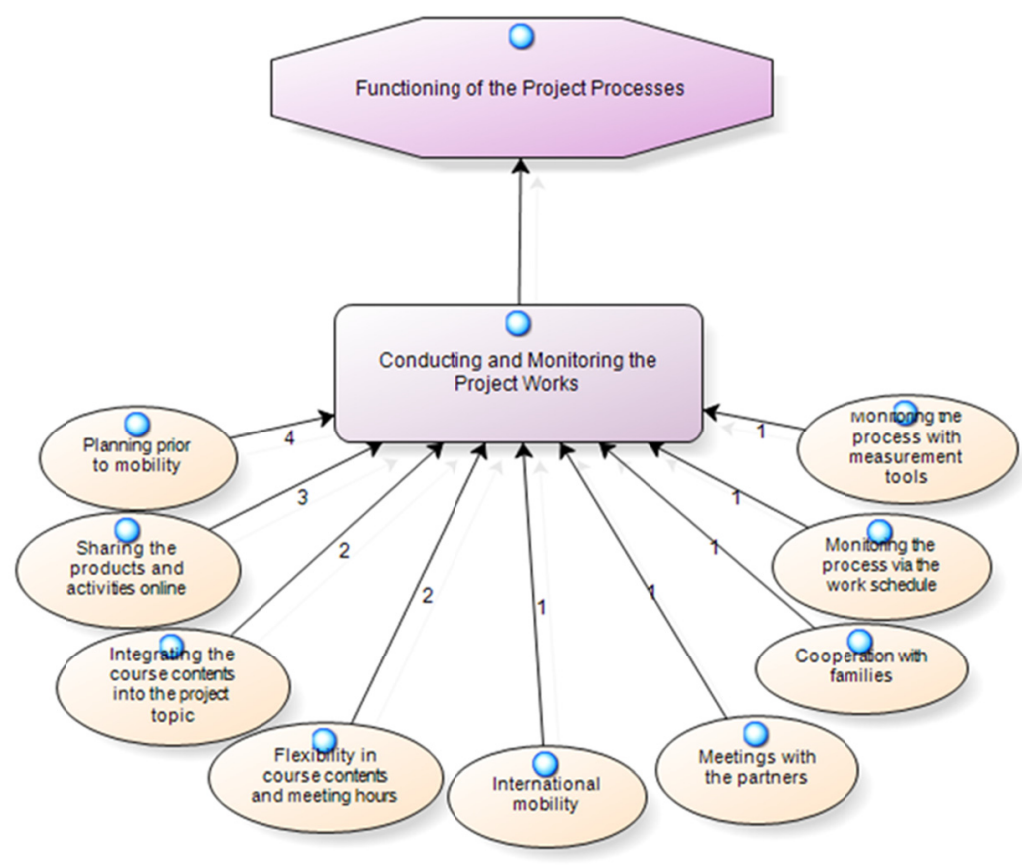

Figure 2. Activities carried out in the process of conducting and monitoring of the project works

As can be seen in Figure 2, in the process of conducting the project works, activities like planning prior to mobility, sharing the products and activities online and integrating course contents into project topic were carried out by more than one participant. In addition, two of the participants mentioned the flexibility brought into the course contents and the meeting hours in the process. Also, it was seen that in the phase of monitoring the process, the participants mentioned the communication established with the families and that they monitored the process by using a work schedule and different measurement tools. In relation to the importance of planning prior to mobility, one of the teachers said:

Every day, this issue was unavoidably brought into agenda. Well, there were always questions like 'what time will we go? Is there any answer? And this and that. We didn't talk about any other thing in those two years. We always talked about these issues, and we knew everything about these issues like 'that mail has been received; we have replied to them; and so on. We constantly talked to each other about these issues. For example, someone asks me 'what are you doing?' Sometimes, at the end of school days,... I saw the teacher; we did these and those in the music room. From time to time, the teacher put forward ideas about the musical pieces to be played. I mean we always had dialogues like these (Melih, p. 3).

Figure 3 presents the categories and sub-categories regarding the activities carried out by the teachers in the process of evaluation of the project works. 


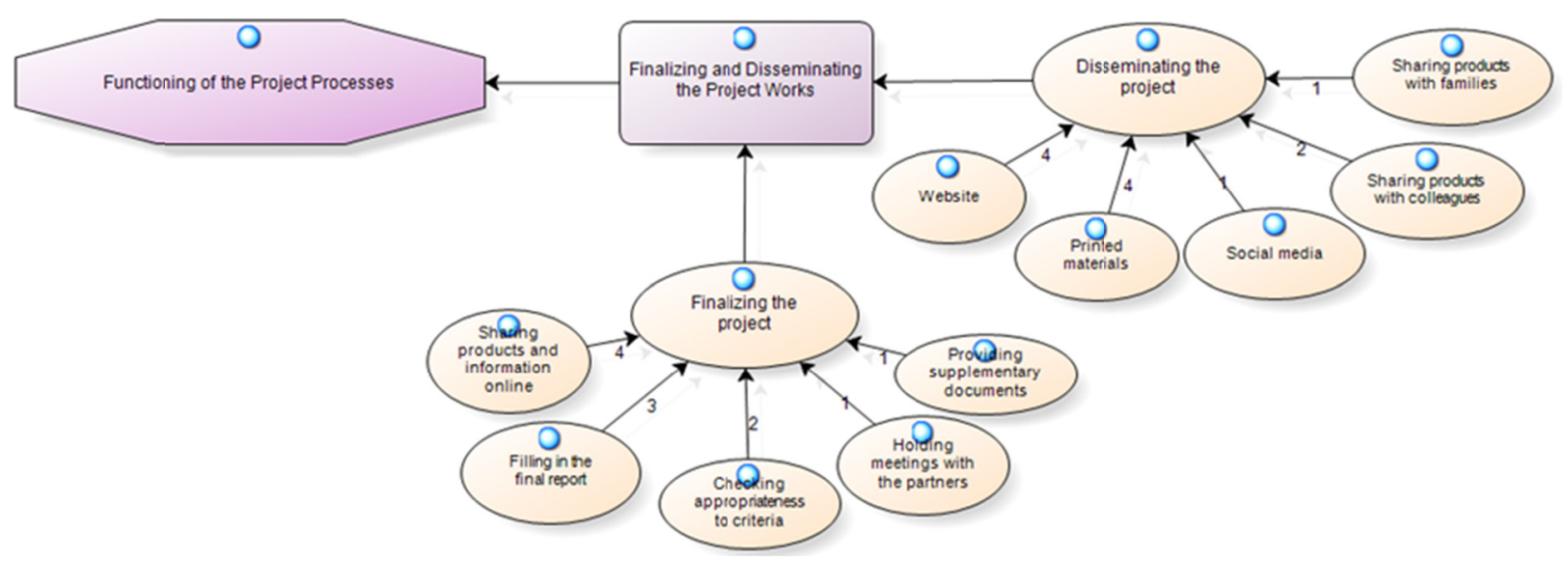

Figure 3. Activities carried out in the process of finalizing and disseminating the project works

When Figure 3 is examined1, it is seen that while finalizing their project works, the teachers shared the products and the necessary information online, filling in the final report, checked appropriateness to the criteria, held meetings with the partners and provided the supplementary documents. For the sake of the dissemination of the project, they used such tools as websites, printed materials and social media and shared the projects with colleagues and families in the process. One of the teachers explained the process of filling in the final report while finalizing the project:

While finalizing the project, there is a website on the Internet. It is about European Union mobility. We are supposed to share some information about what we have done here via that website. We shared information about the road, distance calculation, the budget, and there was a part called 'report'. We were expected to prepare a report about what we had done besides what was planned and about to what extent we achieved the goals. We filled in that report via the website on the Internet (Sinan, p. 4).

Another participant mentioned the activities carried out for the dissemination of the projects, saying:

During the activities carried out for the dissemination of the projects, we effectively used the website of the project and the website of the school. Also, we published the related news in local press. We held introductory meetings with the teachers working at schools in the city (Banu, p.5).

\subsection{Personal and Professional Contributions of the Project Works}

In relation to another dimension of the findings obtained, the participants mentioned the personal and professional contributions of the project processes to them. Figure 4 shows the categories regarding the participants' related views.

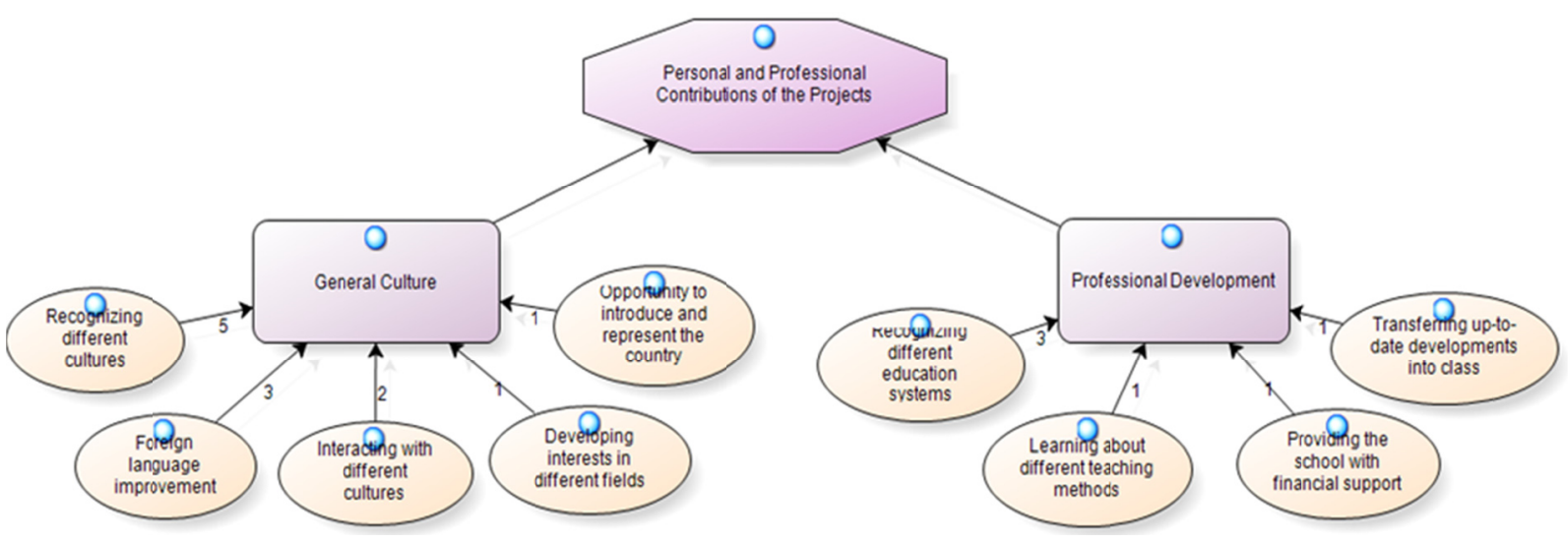

Figure 4. Personal and professional contributions of the project works

When Figure 4 is examined, it is seen that the participants mostly mentioned the contributions of the project works into the field of general culture. In this respect, such issues as recognizing different cultures, communicating with different cultures and improvement of foreign language were mentioned by more than one participant. Also, one participant stated that the project works provided opportunities to develop interest in different fields, and another participant pointed out that the project works allowed them to introduce and represent their country. One of the students who 
pointed to recognition of different cultures said:

As I said before, thanks to this project, I visited seven, or eight, countries in two years. We compared our schools with the schools in these countries. We were introduced to people there. We went there for project purposes, but visiting other countries even as a trip really contributes to a person's life a lot (Melih, p. 8).

It was found that in relation to the contribution of the project works to professional development, the participants mostly mentioned recognition of different education systems. In addition, the participants reported that the project works allowed learning about different teaching methods, transferring up-to-date developments into class environment and providing the school with financial support. One of the project members, who was a teacher of the Social Studies Course, mentioned professional contributions of project works, saying:

I had the opportunity to learn about education systems in other countries. I recognized that they are all the same. I mean, for example, the classes are the same. As Ireland is quite a rich country, it is a bit different from us. Poland and Italy are poor like us. Also, their populations, and the geographical formations... I learned a lot of detailed information about these countries (Derya, p. 9).

\subsection{Factors Making the Project Processes Difficult}

Figure 5 presents the categories and sub-categories regarding the participants' views about the factors that made the project processes difficult.

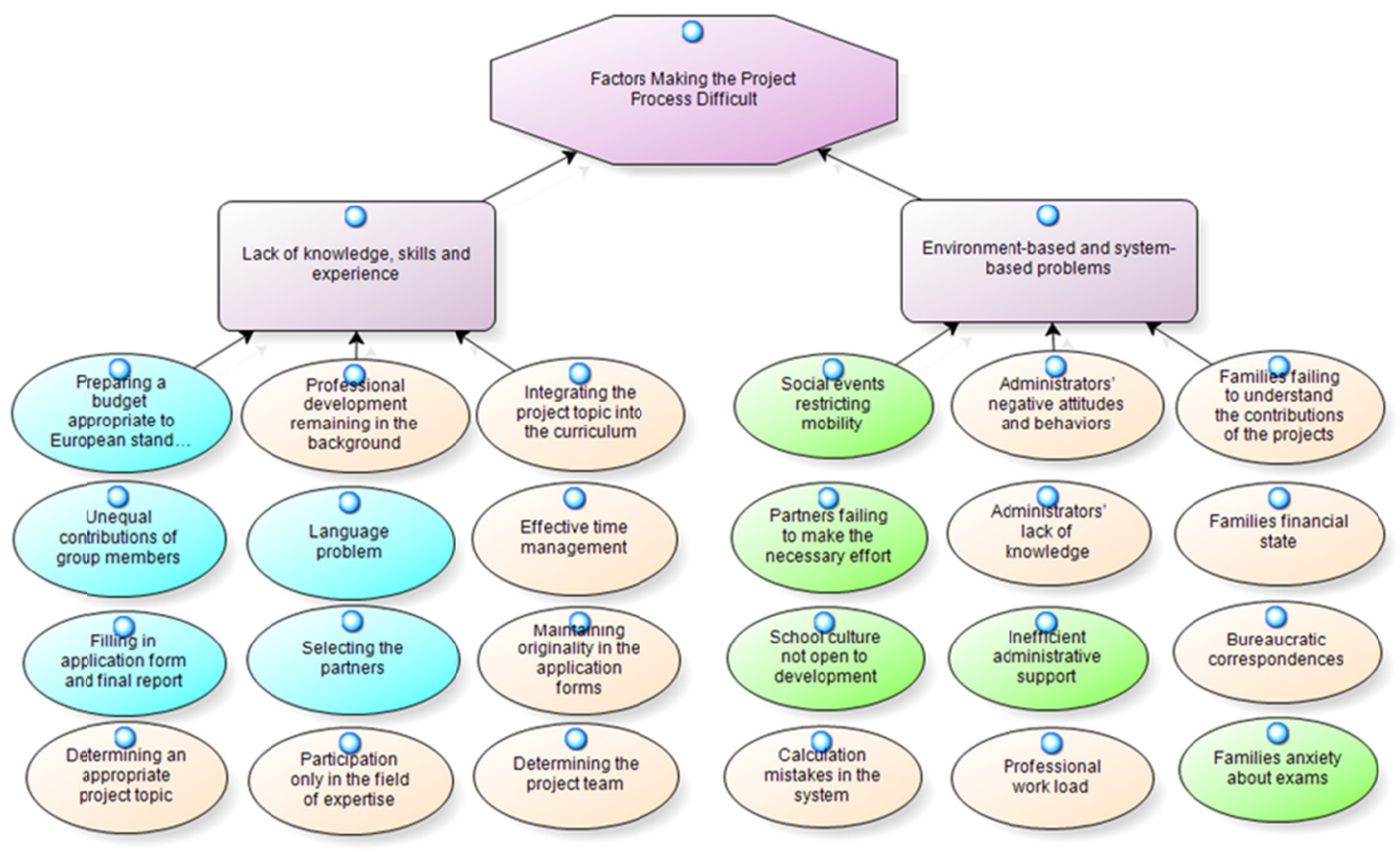

Figure 5. Factors making the project processes difficult

As can be seen in Figure 5, the first dimension of the problems experienced by the participants in the process was related to lack of knowledge, skills and experience. In this respect, it was seen that the participants mostly had difficulty in preparing a budget plan appropriate to the European standards ( $\mathrm{f}: 2$ ), filling in the application form and final report (f:2) and selecting the partners (f:2) and that unequal contributions of the group members (f:2) and the language problem (f:4) made the process difficult. The other problems based on lack of knowledge, skills and experience constituted the dimensions of determining appropriate project topic, integrating the project topic into the curriculum, forming the project team, ensuring originality of the application form and effective time management. One of the participants mentioning the difficulties they experienced due to their language problem said:

Another problem was that neither the teachers nor the students can speak a foreign language. In the group called Turkey, only the teachers of English Language can speak a foreign language, and this makes us quite weak partners. In other countries, the teachers and the students did not have any language problem, so I can say the biggest deficiency was lack of a foreign language (Banu, p. 4).

In the other dimension of the factors making the process difficult, the participants mentioned the problems based on the environment and on the system. These problems, which included social events restricting mobility (f:3), partners' failure 
to make the necessary effort (f:2), school culture not open to development (f:3), inefficient administrative support (f:3) and families anxiety about exams (f:2), were mentioned by more than one participant. Among the other problems were the calculation mistakes in the system, the administrators' negative attitudes and behaviors and their inefficient knowledge, professional workload, families' failure to understand the contributions of the projects, families' financial states, and bureaucratic correspondences. One of the participants who stated that $\mathrm{s} /$ he experienced difficulty due to the school culture not open to development said:

The other teachers did not support us in their lessons. They did not put music into the foreground in the teaching process... Therefore, I can say it was not efficient. Actually, we of course gained something. Our teachers did not provide any support just because they are teachers. They come and teach their lessons. I mean they are just teachers. Also, there is no mission, vision or openness to change...(Derya, p. 11).

\subsection{Suggestions Regarding the Development of the Project Processes}

Figure 6 presents the categories and sub-categories regarding the participants' suggestions for the development of the project processes.

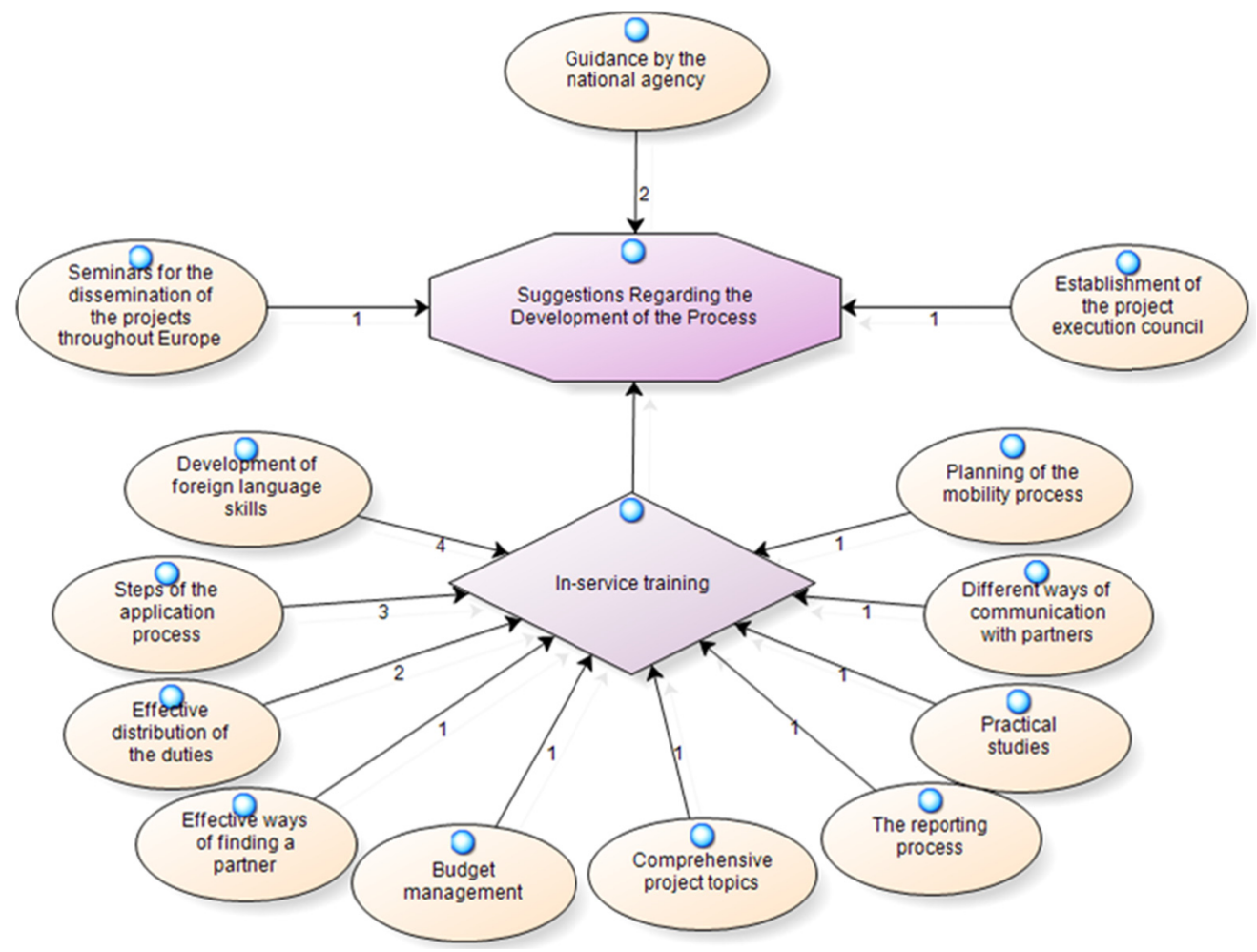

Figure 6. Suggestions regarding the development of the project processes

As can be seen in Figure 6, the participants suggested structural regulations like guidance by the national agency, seminars for the dissemination of the projects throughout Europe and establishment of the project execution council and reported that they needed an in-service training for the development of process. One of the participants mentioning the importance of guidance by the national agency said:

Alternative spontaneous solutions can be put forward by consulting national agency experts... Also, the related person could be asked to pay the cost (Ahmet, p. 3).

In the study, it was seen that the in-service training suggested by the participants should cover development of foreign language skills, steps of the application process, effective distribution of duties, budget management and practical studies. In addition, according to the participants, the trainings to be organized should not only focus on putting forward effective ways to find a partner, on determining project topics as well as on planning the mobility process but also put forward different ways of communication with partners. One of the participants mentioning the development of foreign language skills said:

I told this in all the seminars. They really have to speak a foreign language. Well, they are just filling in the application form, and it is 64 pages. And some forms include 67 pages, and some 62. But they never use Turkish while filling in the forms. Therefore, we have to speak English (Oya, p. 10). 
Another participant who worked as a coordinator in the projects stated that the in-service trainings should cover the steps of the project application processes and said:
I know all of them now. I don't have any specific demand for the moment. For those new beginners, I would ask them to explain what to write down in each section of the application form, how to write it and what to mention because the trainings are too general; they do not provide any detail (Banu, p. 5).

\section{Discussion, Conclusion and Implications}

The findings obtained in the study revealed that the teachers preparing for school education projects determined the project topics filled in the application forms, prepared the activities and distributed the duties. In addition, it was found that several activities were carried out to execute, evaluate and maintain the process via such activities as disseminating the project works, planning prior to mobility, sharing information and products with partners, filling in the final report and checking appropriateness to the criteria. In other studies investigating teachers' views about project processes, similar results were obtained in that the participants in these studies generally mentioned activities like determining the project topic, labor division regarding the activities, determining the partners and sharing the products in the process of mobility (Barzanò, 2002; Gutiérrez Colón-Plana, 2012; Öztürk, 2016; Türkoğlu \& Türkoğlu, 2006).

In addition, it is seen in the guide prepared by the National Agency that in relation to planning before application, special importance is given to such issues as appropriateness to programme criteria and checking financial conditions (Turkish National Agency, 2017) and that the phases of the project application process in the international platform were explained in detail with the support of visuals (European Commission, 2016). In this respect, the findings demonstrated that the teachers mostly took the suggested basic phases into account for the activities they carried out in relation to planning, implementation and evaluation of the project processes. In addition, when the findings were elaborated, it was revealed that the coordinator had the responsibility in such activities as filling in the application form and final report which directed the whole process and sharing the products and activities and that the other members took active roles in some phases of the process. This situation demonstrates that there were some problems with the selection of the group members while planning the project works and that the duties were not effectively distributed among the group members. This view is also supported by the finding that the participants mentioned unequal contributions of the group members. However, it was seen that with the school education projects within the scope of Erasmus + , different areas were created for the development of the teachers' social skills, their effective communication skills and their group work skills. In addition, among the goals of project processes is to allow institutions to do self-evaluation with a more autonomous approach and to determine the areas they need to develop (Barzanò, 2002).

The fact that the opportunities provided by project processes lead to problems rather than development could be associated with the dependence between group members, with lack of motivating factors influential on this dependence and with inefficient development of the institutional culture. This view is also supported by the fact that the participants mentioned such environment-based and system-based problems as inefficient administrative support and the school culture not open to development. In one study carried out by Kassel (2007), it was reported that the problems frequently experienced in the process of execution of projects include local administrators or teachers' lack of interest and support in the process who are actually expected to take an active role in projects. In another similar study, it was revealed that the participants experienced problems in relation to taking responsibility and working in groups in the process of execution of the projects (Yalçın-İncik \& Yanpar-Yelken, 2009). Therefore, as suggested by Akay and Yanpar-Yelken (2012), while forming the project team, personal characteristics and academic proficiencies of teachers willing to take part in the process should be taken into account. When examined in more detail, the findings also pointed out that project coordinators should be informed about the selection of group members. In addition, it is thought that more concrete regulations are necessary to increase administrators' support for project processes and to support teachers' participation in project works. These regulations could include not only increasing the financial funds provided for schools, administrators and teachers taking part in project processes but also providing administrators and teachers with the opportunities to be promoted within and out of the institution.

When the other problems experienced in the process were examined, it was seen that the participants had difficulty more in such issues as preparing a budget plan appropriate to European standards, filling in the application form and final report and selecting the partners. The results reported by Haspolat and Özkıliç (2007) who found that the most important difficulty experienced by project coordinators was related to finding partners and filling in application forms are consistent with the related findings obtained in the present study. In addition, other similar studies also revealed that participants experience difficulty in the application process, and based on the results, increasing their levels of knowledge about the process was suggested (Bahadır, 2007; Bozak, Konan \& Özdemir, 2016; Helsinki University, 2003; Türkoğlu \& Türkoğlu, 2006).

Another dimension of the findings obtained was related to the personal and professional contributions of the project 
processes. In this respect, it was found that the project works made important contributions to developing language skills, establishing interaction with different cultures and recognizing different cultures. This finding is parallel to those obtained in other national and international studies which reported that project works allow participants to recognize and understand different cultures, to raise awareness of different cultures, to encourage intercultural communication and to develop language skills (Akay \& Yanpar-Yelken, 2012; Aydoğan \& Şahin, 2016; Barzanò, 2002; Bozak, Konan \& Özdemir, 2016; Haspolat \& Özkılıç, 2007; Kesik \& Balcı, 2016; Kulaksız, 2010; Liduma, 2014; Tatlı, 2016; Öztürk, 2016; Yalçın-İncik \& Yanpar-Yelken, 2009). On the other hand, one striking finding obtained in the present study was that there was a limited number of participants mentioning professional development and that these participants mostly pointed to the contribution of project works to the recognition of different education systems. The results of another study carried out by Kulaksiz (2010) demonstrated that Erasmus ${ }^{+}$school education projects contribute to encouragement of intercultural communication and that the contribution of the projects to increasing the quality in education was not at the desired level, though. In the related study, it was also found that the goals of participants in Turkey mostly include visiting other countries, bringing prestige to school, and meeting other teachers and administrators in other schools participating in the projects.

The priorities of the National Agency (2017) in the field of school education include informing teachers and school administrators about effective teaching methods and about information and communication systems, coping with culturally-mixed classroom environments, and acquiring such skills as using new teaching methods and tools in class. In addition, it is pointed out that new teaching methods and materials and language skills should be developed with the help of school education projects (Gordon, 2001; Kirss \& Uus, 2007). International studies and the reports in European Union countries show that the goals in question have been achieved to a great extent. Related studies demonstrate that project processes contribute positively to the development of innovative teaching approaches, to the communication between teachers and students as well as to student motivation (Barzanò, 2002; Dumitrescu et.al., 2014; Gutiérrez Colón-Plana, 2012; Helsinki University, 2003; Somekh et.al., 2007; Talmo et.al., 2014; Thorsteinsson \& Page, 2008; Viladot et.al., 2017).

In addition, while international studies provide important data regarding the contributions of projects to professional development of teachers, the findings obtained in these studies also demonstrate that professional development targeted by Erasmus + school education projects remains limited to such basic information as recognizing different education systems. In this respect, it is thought that the skill-related outcomes have not been achieved at all. Participants' lack of knowledge, skills and experience in relation to the functioning of the projects could be regarded as an important factor restricting professional development. The reason is that in order to achieve professional development at the desired level, functioning of school education projects should be integrated into the curricula. This integration process requires teachers to associate project topics with the learning outcomes and to carry out activities appropriate to the project goals in the teaching process. Also, for the purpose of achieving professional development at the desired level, participants' knowledge and skills regarding the functioning of projects and the integration of these projects into the curriculum should be developed. Results of other studies supporting this view demonstrate that teachers' related knowledge, skills and experience are among the basic factors influential on the success of the projects (Akay \& Yanpar-Yelken, 2012; Bahadır, 2007; Gordon, 2001; Gutiérrez Colón-Plana, 2012; Romano, 2002; Tatl1, 2016; Yalçın-İncik \& Yanpar-Yelken, 2009; Viladot et.al., 2017). Regarding the suggestions for the development of the process, it was found that most of the participants needed an in-service training on Erasmus+ school education projects. Moreover, the participants' views about the contents of such in-service trainings revealed that they mostly focused on foreign language skills, on the steps of the application process and on effective distribution of the duties. The participants also mentioned such dimensions as budget management, determining the project topics, the reporting process, mobility and communication with the partners. When the participants' suggestions regarding the development of projects were examined as a whole, it was seen that they pointed to the need for an education process which is supported by practical studies for the acquisition of skills. These views of the participants are consistent with the results of other related studies (Önen, Mertoğlu, Saka \& Gürdal, 2010; Tatl1, 2016; Türkoğlu \& Türkoğlu, 2006) which draw attention to the importance of practical studies for the improvement of project processes.

Consequently, in the present study, it was found that the teachers had certain knowledge about the planning, implementation and evaluation of Erasmus + school education projects and that they failed to acquire the necessary skills at the desired level, though. It was also revealed that the group work process and lack of knowledge, skills and experience regarding the process were among the factors making the functioning of the projects difficult and that professional development was not achieved at all.

All these results demonstrate that teachers are in need of an in-service training which focuses more on the steps of the application process, which involves integration of project goals into the curriculum and which aims to help acquire the related skills by considering the functioning of projects as a whole. Furthermore, it is thought that there is a need for 
structural regulations which inform local governments and school administrators about the contributions of European Union projects and which encourage teachers participating in these projects to take a more active role.

Lastly, the results obtained in the present study were limited to the views of eight participants. For this reason, future studies could be carried out with a more comprehensive study group to determine and deal with the educational needs of teachers regarding European Union project processes.

\section{Note}

This study was presented at 26th International Conference on Educational Sciences (April 20-23, 2017, Antalya, Turkey).

\section{References}

Acir, E. (2008). Searching the comenius projects process in schools. Unpublished master's thesis, Yeditepe University, Turkey.

Akay, C., \& Yanpar-Yelken, T. (2012). The aspects of project attendant teachers about European Union education and youth programmes projects. Social Sciences Research Journal, I, 277-294.

Aydoğan, İ., \& Şahin, A. E. (2006). The contribution of Comenius school partnership projects to achievement of Comenius objectives. Educational Administration: Theory and Practice, 48(48), 455-480.

Bahadır, H. (2007). The opinions of the school administrators and teachers on what level they can benefit from comenius projects. Unpublished master's thesis, Kırıkkale University, Turkey.

Barzanò, G. (2002). School self-evaluation towards a European dimension. European Journal of Teacher Education, 25(1), 83-100. https://doi.org/10.1080/0261976022000012886

Bozak, A., Konan, N., \& Özdemir, T. (2016). The views of teachers school directors and educational inspectors towards European Union educational programs. Gümüşhane University Electronic Journal of the Institute of Social Sciences, 7(15), 1-23. http://dx.doi.10.17823/gusb.192

Center for European Union Education and Youth Programmes (2017a). Erasmus + programme. Retrieved from http://www.ua.gov.tr/

Center for European Union Education and Youth Programmes (2017b). Strategical partnerships in school education. Retrieved from http://www.ua.gov.tr/

Demircioğlu, T., Yavuz-Konokman, G., \& Akay, C. (2015). The effect of proactivity of academicians' at education faculty on their attitudes towards European Union lifelong learning. Electronic Journal of Social Sciences, 15(59), 1120-1137. http://dx.doi.10.17755/esosder.08908

Dilekli, Y. (2008). Analyzing effects of the comenius projects applied in Aksaray the year between 2006-2007 on students, teachers, schools and courses. Unpublished master's thesis, Niğde University, Turkey.

Dumitrescu, C., Drăghicescu, L., Olteanu, R. L., \& Suduc, A. M. (2014). Key competences for sustainable development-aspects related with SUSTAIN project activity. Procedia-Social and Behavioral Sciences, 141, 1101-1105. https://doi.org/10.1016/j.sbspro.2014.05.185

European Commission (2016). Erasmus +: Technical guidelines for completing application e-forms. Retrieved from http://ec.europa.eu

Gordon, J. (2001). The internationalisation of education-schools in Europe and the SOCRATES programme. European Journal of Education, 36(4), 407-419. https://doi.org/10.1111/1467-3435.00078

Gutiérrez Colón-Plana, M. (2012). The reality of Comenius projects in ten Catalan educational institutions. Gist Education and Learning Research Journal, 6, 190-212.

Haspolat, E., \& Özkılıç, R. (2007). The opinions of Comenius school partnership project coordinators about projects process. Eurasian Journal of Educational Research, 7(27), 163-177.

Helsinki University (2003). Intermediate report on the implementation of the SOCRATES programme in Finland (Report No. 41/2003). Finland : Publications of the Ministry of Education.

Kassel (2007). Impact of the comenius school partnerships on the participant schools: Final Report. Germany: Association for Empirical Studies.

Kesik, F., \& Balc1, E. (2016). Evaluation of The EU projects in terms of the contributions to schools: A scale development study. Kastamonu Education Journal, 24(4), 1621-1640.

Kirss, L., \& Uus, M. (2007). National report on the implementation of the Socrates and Leonardo programmes: Estonia. 
Tallinn: PRAXIS Center for Policy Studies.

Kulaksiz, E. (2010). The participant's opinions of the implemantations of European Union Comenius programmes in Turkey. Unpublished doctoral dissertation, Kocaeli University, Turkey.

Lembet, Z. (2008). The contribution of cultural interaction of European Union education an exchange program's in learning foreign language. Unpublished master's thesis, Gazi University, Turkey.

Lichtman, M. (2012). Qualitative research in education: A user's guide. Thousand Oaks: Sage Publications.

Liduma, A. (2014). Citizenship promotion opportunities: reflections on the Comenius project 'me and my Europe: Intercultural challenges of modern pre-primary education. In P. Cunningham \& N. Fretwell (Eds.), Innovative practice and research trends in identity, citizenship and education (pp. 280-285). London: CiCe.

Öksüm-Erdoğan, D. (2009). Evaluation of Comenius program's level of achieving its goals according to the opinions of administrators and teachers taking part in the program. Unpublished master's thesis, Kirıkale University, Turkey.

Önen, F., Mertoğlu, H., Saka, M., \& Gürdal, A. (2010). The effects of in service training on teachers' knowledge about project-based learning and competencies for conducting projects: Öpyep case. Ahi Evran University Journal of Education, 11(1), 137-158.

Öztürk, E. (2016). Evaluation of effectiveness of European Union's Comenius program according to attending teachers'opinions. Unpublished master's thesis, Uşak University, Turkey.

Romano, M. (2002). Training teachers for quality education in Europe. European Journal of Teacher Education, 25(1), 11-17. https://doi.org/10.1080/0261976022000012822

Somekh, B., Lewin, C., Saxon, D., Woodrow, D., Sing, S., \& Convery, A. (2007). Evaluation of the ICT test bed Project: The qualitative report. Retrieved from http://www.evaluation.icttestbed.org.uk.

Talmo, T., Radojicic, K., Orevi, M., Ramstrand, A., \& Mogli, M. (2014). Identifying the logical structure of languages by use of new interactive mobile services, new diagnostic training methods for development of key competences, and new evaluation methods introducing assessment for learning practices. Retrieved from http://histproject.no/sites/histproject.no/files/D\%207_1\%20-\%20Exploitation\%20strategy\%20guideline\%20in\%20 English.pdf

Tatl1, Z. (2016). Teachers opinions about project development processes. YYU Journal Of Education Faculty, XIII(I), 631-656.

Thorsteinsson, G., \& Page, T. (2008). Blended learning approach to improve in-service teacher education in Europe through the FISTE Comenius 2.1 project. Educatia, 21, 291-297.

Turkish National Agency (2017). Erasmus+ KA2- stratejik ortaklıklar: Okul eğitimi stratejik ortaklık projeleri başvuru rehberi. Retrieved from http://www.ua.gov.tr.

Türkoğlu, Ş., \& Türkoğlu, R. (2006). The views of school managers and coordinator teachers who applied to Comenius 1 school partnership projects. Inonu University Journal of the Faculty of Education, 7(12), 125-154.

Vabo, A. (2007). Evaluation of the Leonardo da Vinci and SOCRATES programmes in Norway: Final report (Report No. 26/2007). Oslo: NIFU STEP.

Viladot, L., Hilton, C., Casals, A., Saunders, J., Carrillo, C., Henley, J., ... Welch, G. (2017). The integration of music and mathematics education in Catalonia and England: Perspectives on theory and practice. Music Education Research, 1-12. https://doi.org/10.1080/14613808.2017.1290595

Yalçın-İncik, E., \& Yanpar-Yelken, T. (2009). Elementary school teachers opinions about the European Union education projects. e-Journal of New World Sciences Academy, 4(3), 923-940.

Yıldırım, A., \& Şimşek, H. (2006). Sosyal bilimlerde nitel araştırma yöntemleri. Ankara: Seçkin Yayıncılık.

Yin, R. K. (2013). Case study research: Design and methods. Sage publications.

\section{Copyrights}

Copyright for this article is retained by the author(s), with first publication rights granted to the journal.

This is an open-access article distributed under the terms and conditions of the Creative Commons Attribution license which permits unrestricted use, distribution, and reproduction in any medium, provided the original work is properly cited. 